\title{
Stochastic Response Characteristic and Equivalent Damping of Weak Nonlinear Energy Dissipation System under Biaxial Earthquake Action
}

\author{
Yu Xia, Ze Wu, Zhemin Kang, and Chuangdi Li \\ Civil Engineering and Architecture Department, Guangxi University of Science and Technology, Liuzhou 545006, China \\ Correspondence should be addressed to Yu Xia; summ-rain@163.com
}

Received 24 January 2017; Accepted 12 April 2017; Published 10 May 2017

Academic Editor: Roman Lewandowski

Copyright (C) 2017 Yu Xia et al. This is an open access article distributed under the Creative Commons Attribution License, which permits unrestricted use, distribution, and reproduction in any medium, provided the original work is properly cited.

\begin{abstract}
The random response characteristic of weak nonlinear structure under biaxial earthquake excitation is investigated. The structure has a SDOF (single degree of freedom) with supporting braces and viscoelastic dampers. First, it adopts integral constitutive relation and establishes a differential and integral equations of motion. Then, according to the principle of energy balance, the equation is linearized. Finally, based on the stochastic averaging method, the general analytical solution of the variance of the displacement and velocity response and the equivalent damping is deduced and derived. At the same time, the joint probability density function of the amplitude and phase and displacement and velocity of the energy dissipation structure are also given. The dynamic characteristics of a structure with viscoelastic dampers are determined as a solution to the variance of displacement response, so the equivalent damping is taken into consideration as a solution to replace the original nonlinear damping. It means it has established a unified analytical solution of stochastic response analysis and equivalent damping of a SDOF nonlinear dissipation structure with the brace under biaxial earthquake action in this paper.
\end{abstract}

\section{Introduction}

In addition to the two seismic force components in the horizontal direction, there is still vertical seismic force components. Actual earthquake structure is always subject to vertical and horizontal earthquake actions. Under a larger action of earthquake, the response of structure is further increased. At this time, the vertical earthquake action can not be ignored. Therefore, it is important to research structure response in the horizontal and vertical earthquake. As land in big cities is limited, buildings are located close to each other. To reduce the seismic responses of buildings, adjacent buildings are linked together by connecting dampers, such as the Triple Towers in Downtown Tokyo [1]. Researchers have proposed different types of connecting devices to connect adjacent buildings. These devices include passive dampers [2-5], semiactive dampers [6-8], and active dampers [9, 10]. It is now well recognized that seismic responses of adjacent buildings can be mitigated by connecting dampers. Biaxial earthquake action will aggravate the vibration of the structure; the devices of passive control will reduce the structural vibration. The passive control techniques, such as viscous and viscoelastic dampers, have been widely used [11]. Linear viscoelastic damper is a kind of excellent performance of energy dissipation device and is widely used in seismic engineering. The integral model is the most general model of viscoelastic dampers [12]. Other models, such as the complex modulus model [13], the fractional derivative model [1416], and the general differential model, are all approximate model. Analytical modeling of a novel type of passive friction damper for seismic hazard mitigation of structural systems is present [17]; numerical results show that the proposed damper is more efficient in dissipating input seismic energy than a passive linear viscous damper with same force capacity. The equivalent linearization of the motion equations with Maxwell dampers will effectively solve the problem of nonlinear equations. A system with nonlinear dampers is usually replaced by an equivalent linear system, with its properties determined by using different methods, like equating the energy dissipated [18], equating power consumption [19], 
replacing the nonlinear viscous damping by an array of frequency and amplitude-dependent linear viscous models [20], and other random vibration theories [21]. Malone and Connor [22] have reported a method setting a new degree of freedom at mass-less point between a dashpot and a stiffness spring of the Maxwell model and then apply a common numerical integration scheme. In this method, it is necessary to consider twice the degrees of freedom of the original system. It has been mainly applied to the analyses of material stress-strain relationships. Kitagawa et al. [23] have reported the analysis of reinforced concrete elements by considering the effect of strain speed. They treated the Maxwell model as a supplementary restoring force on the equation of motion of the system discretized by a central difference method, which is categorized into an explicit integration scheme. It can play a better role of shock absorption by adding brace to the viscoelastic damper. The brace is widely used in damper. The integral model is a typical type; this kind of damper [12] can be used to describe the instantaneous elasticity, creep, relaxation, and strain memory of viscoelastic dampers. Park et al. [24] and Singh et al. [25] describe the use of gradientbased optimization algorithms to obtain the optimal parameters of dampers and their supporting braces in structures subjected to seismic motions. More recently, Chen and Chai [26] also proposed a gradient-based numerical procedure for determining the minimum brace stiffness together with a set of optimal damper coefficients to meet a target response reduction. They used Maxwell model-based brace-damper systems and concluded that brace stiffness equal to the first storey stiffness would be adequate for the desirable levels of response reduction in typical applications. Since the structure is installed with the damper and then turned into the energy dissipation structure, its design can not be directly applied to the response spectrum method. At the same time, this makes the design of actual engineering very inconvenient. The damping ratio of the dissipation system is the sum of the damping ratio of the structure itself and the equivalent damping ratio of the damper. The linear response spectrum method can be used to calculate the equivalent damping ratio of the damper $[27,28]$. Therefore, it is greatly significant to establish a equivalent structure. Then, the response spectrum method can be used directly used to structural analysis and engineering design. The relationships between equivalent damping and ductility for the direct displacement-based seismic design (DBSD) method are proposed [29]. As the concept of the DBSD is addressed to highlight the importance of the proper determination of equivalent damping, in the DBSD, the equivalent stiffness is taken as the secant stiffness at maximum deformation, so the appropriate equivalent damping should be determined based on such a prescription. And twenty-one SDOF systems are designed according to the DBSD procedure and analyzed to indicate that the proposed equivalent damping relationships are suitable for the DBSD. In addition, stochastic averaging method is an effective approximation method for predicting the stochastic response of a structure. The basic assumption is small damping and weak broadband excitation. Compared with the modal strain energy method, it is easy to understand and obtain the general analytical solution under a close theoretical basis; the same result of decoupling method of the forced vibration mode under the case of linear small damping can be concluded. In fact, in recent years, the important theoretical results of linear and nonlinear random vibration are obtained by using the stochastic averaging method. It investigates the stochastic response of vibroimpact system with fractional derivative under Gaussian white noise excitation; the nonsmooth transformation and stochastic averaging method are used to obtain the analytical solutions of the equivalent stochastic system [30]. The first-passage statistics of DuffingRayleigh-Mathieu system under wide-band colored noise excitation are studied by using stochastic averaging method. The motion equation of the original system is transformed into two time homogeneous diffusion Markovian processes of amplitude and phase after stochastic averaging [31]. The equivalent linearization can solve the problem of nonlinear structure; a nonlinear stochastic optimal control strategy for single degree of freedom viscoelastic system with actuator saturation is proposed based on the stochastic averaging method and stochastic dynamical programing principle. As the viscoelastic system is converted into an equivalent nonlinear nonviscoelastic system by replacing the viscoelastic force with amplitude-dependent stiffness and damping [32], in this paper, it has used the equivalent linearization method and the stochastic averaging method, and it has also used the general integral model of viscous and viscoelastic dampers. Considering the comprehensive effect of brace, strain history of damper, dynamic characteristics of structure, and excitation, it establishes a complete analytical solution of stochastic response analysis and equivalent damping of a SDOF nonlinear dissipation structure with the brace under biaxial earthquake action. The new approach can be directly applied to damping engineering design with the response spectrum method.

\section{Constitutive Equation of Damper with Brace}

2.1. Motion Equation of Maxwell Damper with Braces. The mass matrix, stiffness matrix, and damping matrix of the structure are $m, k$, and $c$, respectively. A viscoelastic damper $\left(p_{1}(t)\right)$ of the general integral type is equipped between floors. The modified damper with supporting braces $\left(k_{b 1}\right)$ is $p_{G 1}(t)$. The complex modulus, storage modulus, and energy dissipation modulus of $p_{1}(t)$ and $p_{G 1}(t)$ are $E_{\mathrm{Q} 1}(1 w), E_{\mathrm{Q} 11}(\omega)$, $E_{\mathrm{Q} 21}(\omega)$ and $E_{\mathrm{G} 1}(1 \omega), E_{\mathrm{G} 11}(\omega), E_{\mathrm{G} 21}(\omega)$, respectively. The relaxation modulus, equilibrium modulus, and relaxation function of $p_{1}(t)$ and $p_{G 1}(t)$ are $Q_{1}(t), k_{\mathrm{Q} 1}, h_{\mathrm{Q} 1}(t)$ and $G_{1}(t)$, $k_{G 1}, h_{G 1}(t)$, respectively. The displacement vector of the structure with respect to the ground is $u$ when the horizontal and vertical ground motion are $\ddot{u}_{g}(t)$ and $\ddot{u}_{v}(t)$; the relative displacement of damper $p_{1}(t)$ and its supporting braces $\left(k_{b 1}\right)$ are $u_{p 1}$ and $u_{b 1}$, respectively; two dampers mentioned above are shown in Figures 1 and 2.

The motion equation can be expressed as follows:

$$
\begin{aligned}
m & \{\ddot{u}\}+c\{\dot{u}\}+k\{u\}+P_{G 1}(t) \\
& =-m\left[\left\{R_{u}\right\} \ddot{u}_{g}(t)+\left\{R_{v}\right\} \ddot{u}_{v}(t)\right],
\end{aligned}
$$

where $m$ is the mass, $c$ is the damping, $k$ is the stiffness, and $\left\{R_{u}\right\}$ and $\left\{R_{v}\right\}$ are horizontal and vertical inertial force vector. 


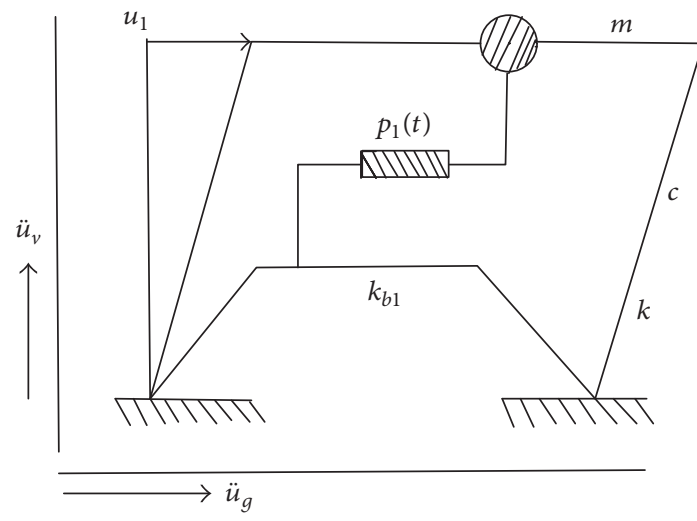

(a) The original calculation diagram of structure

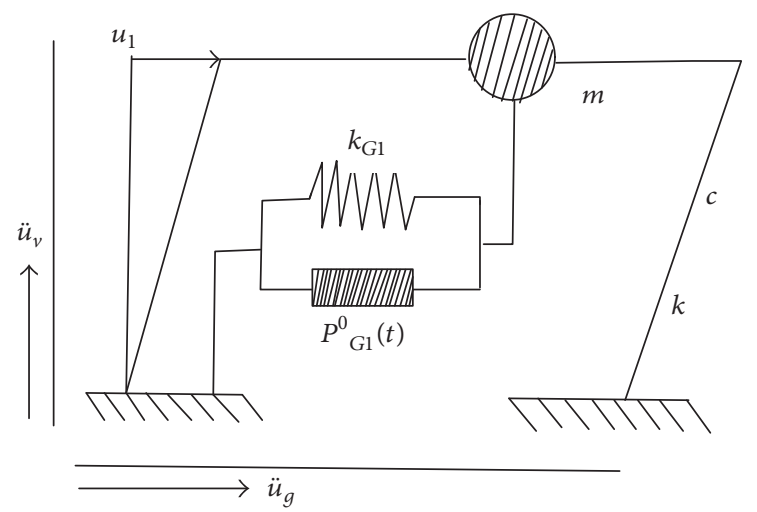

(b) The modified calculation diagram of structure with brace

FIGURE 1: Calculation diagram of structure.

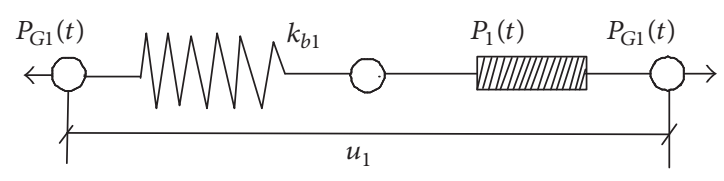

(a)

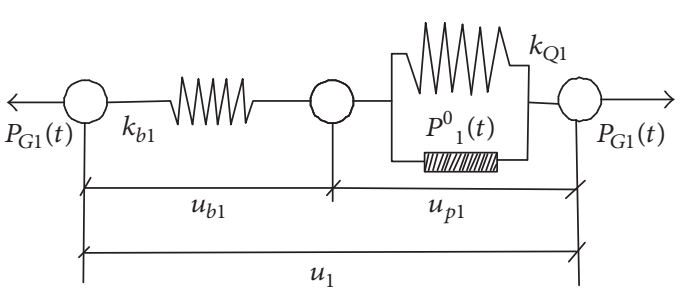

(b) The original calculation diagram of damper

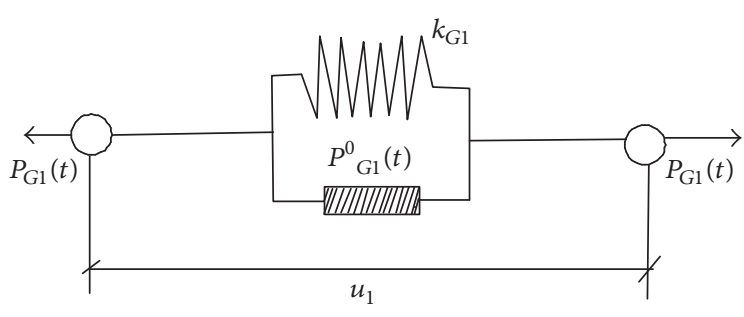

(c) The modified calculation diagram of damper with brace

Figure 2: Calculation diagram of damper.

$p_{G 1}(t)$ is the viscoelastic dampers force. Relevant parameters are listed as follows:

$$
\begin{aligned}
k_{G 1} & =\frac{k_{b 1} k_{\mathrm{Q} 1}}{k_{b 1}+k_{\mathrm{Q} 1}}, \\
p_{G 1}(t) & =k_{G 1} u+p_{G 1}^{0}(t), \\
p_{G 1}{ }^{0}(t) & =\int_{0}^{t} h_{G 1}(t-\tau) \dot{u}(\tau) d \tau \\
E_{G 11}(\omega) & =\frac{k_{b 1}\left[E_{\mathrm{Q} 11}^{2}(\omega)+E_{\mathrm{Q} 21}^{2}(\omega)+k_{b 1} E_{\mathrm{Q} 11}(\omega)\right]}{\left[k_{b 1}+E_{\mathrm{Q} 11}(\omega)\right]^{2}+E_{\mathrm{Q} 21}^{2}(\omega)} \\
E_{\mathrm{G} 21}(\omega) & =\frac{k_{b 1}{ }^{2} E_{\mathrm{Q} 21}(\omega)}{\left[k_{b 1}+E_{\mathrm{Q} 11}(\omega)\right]^{2}+E^{2}{ }_{\mathrm{Q} 21}(\omega)} .
\end{aligned}
$$

\section{The Vibration Equation of Weak} Nonlinear System with Single Degree of Freedom and Its Linearization

3.1. The Transfer of the Weak Nonlinear System Equation. Considering the weak nonlinear SDOF system, the general energy dissipation structural equation can be expressed as follows (see [33, 34]):

$$
\begin{aligned}
m\{\ddot{u}\} & +c\{\dot{u}\}+k u+\varepsilon f(u, \dot{u})+k_{G 1} u \\
& +\int_{0}^{t} h_{G 1}(t-\tau) \dot{u}(\tau) d \tau=-m\left(\ddot{u}_{g}(t)+\ddot{u}_{v}(t)\right),
\end{aligned}
$$

where $m$ is the mass, $c$ is the damping, $k$ is the stiffness, $\varepsilon f(u, \dot{u})$ is the weak nonlinear force including the nonlinear damping and the spring forces, $\left(k_{G 1} u+\int_{0}^{t} h_{G 1}(t-\right.$ $\tau) \dot{u}(\tau) d \tau)$ is the modified damper with supporting forces, and 
$-m\left(\ddot{u}_{g}(t)+\ddot{u}_{v}(t)\right)$ is a biaxial excitation. The main aim is to replace (3) with an equivalent linear one (see [35]).

$$
\begin{aligned}
m \ddot{u} & +c_{e} \dot{u}+k_{e} u+k_{G 1} u+\int_{0}^{t} h_{G 1}(t-\tau) \dot{u}(\tau) d \tau \\
& =-m\left(\ddot{u}_{g}(t)+\ddot{u}_{v}(t)\right)+F_{0} .
\end{aligned}
$$

According to article (see [35]), $F_{0}$ can be expressed as follows:

$$
F_{0}=-\frac{1}{2 \pi}\left[\int_{0}^{2 \pi} f_{m}(A, \varphi) d \varphi+\int_{0}^{2 \pi} f_{k}\left(A_{0}, A, \varphi\right) d \varphi\right]
$$

where $c_{e}$ and $k_{e}$ are the equivalent damping and stiffness, respectively; then the error between solutions of these two systems is minimized with the mean-square method. The difference between (3) and (4) is shown in the following:

$$
\varepsilon_{0}=m \ddot{u}+c \dot{u}+k u+\varepsilon f(u, \dot{u})-m \ddot{u}-c_{e} \dot{u}-k_{e} u-F_{0} .
$$

To get a relative precise result, the error $\varepsilon_{0}$ should be approximating to minimum. It is better to solve the following instead of (6):

$$
\varepsilon_{0}=c \dot{u}+k u+\varepsilon f(u, \dot{u})-c_{e} \dot{u}-k_{e} u-F_{0}
$$

In order to choose the best equivalent damping $c_{e}$ and the equivalent stiffness $k_{e}$, it is necessary to minimize the error with statistical procedure, which requires (7) to be approximating to minimum.

$$
\text { It means } E\left(\varepsilon_{0}{ }^{2}\right)=\text { Minimum, }
$$

where $E\left(\varepsilon_{0}^{2}\right)$ denotes the mathematical expectation.

$$
E\left(\varepsilon_{0}{ }^{2}\right)=E\left[\left(c \dot{u}+k u+\varepsilon f(u, \dot{u})-c_{e} \dot{u}-k_{e} u-F_{0}\right)^{2}\right] .
$$

According to the method of multivariate function, the necessary and sufficient condition (see [36]) for the minimum of $E\left[\varepsilon_{0}^{2}\right]$ is obtained; it requires that

$$
\begin{aligned}
& \frac{\partial E\left(\varepsilon_{0}^{2}\right)}{\partial c_{e}}=0 \\
& \frac{\partial E\left(\varepsilon_{0}^{2}\right)}{\partial k_{e}}=0 .
\end{aligned}
$$

Equations (10) lead to two linear equations and determine the optimal values of $c_{e}$ and $k_{e}$.

$$
\begin{aligned}
& E[\dot{u} f(u, \dot{u})]-c_{e} E\left(\dot{u}^{2}\right)-k_{e} E(u, \dot{u})=0, \\
& E[u f(u, \dot{u})]-c_{e} E(u, \dot{u})-k_{e} E\left(u^{2}\right)=0
\end{aligned}
$$

The required parameters can be obtained simultaneously as follows:

$$
\begin{gathered}
c_{e}=\frac{E\left(u^{2}\right) E[\dot{u} f(u, \dot{u})]-E(u, \dot{u}) E[u f(u, \dot{u})]}{E\left(u^{2}\right) E\left(\dot{u}^{2}\right)-[E(u, \dot{u})]^{2}}+c, \\
k_{e}=\frac{E\left(\dot{u}^{2}\right) E[u f(u, \dot{u})]-E(u, \dot{u}) E[\dot{u} f(u, \dot{u})]}{E\left(u^{2}\right) E\left(\dot{u}^{2}\right)-[E(u, \dot{u})]^{2}}+k .
\end{gathered}
$$

It is known from the paper (see $[37,38]$ ) that $c_{e}$ and $k_{e}$ determined by the above formula lead to the minimum value of $E\left[\varepsilon_{0}{ }^{2}\right]$. It is important to note that it has to solve the linear random vibration system (4) to obtain the optimal values of $c_{e}$ and $k_{e}$.

\section{Statistical Characteristics of Displacement and Velocity Response of Weak Nonlinear Energy Dissipation System under Biaxial Earthquake Action}

4.1. The Transform of the Time Domain Dynamic Equation. The motion equation of equivalent linear structure with viscoelastic dampers (4) could be written in the following form:

$$
\begin{aligned}
\ddot{u}+ & 2 \xi_{1} \omega_{1} \dot{u}+\omega_{1}{ }^{2} u+\beta_{0} \int_{0}^{t} h_{G 1}(t-\tau) \dot{u}(\tau) \\
= & \frac{\left[-\left(\ddot{u}_{g}(t)+\ddot{u}_{v}(t)\right)+F_{0}\right]}{m_{e}},
\end{aligned}
$$

where

$$
\begin{aligned}
\omega_{1}^{2} & =\frac{k_{e}+k_{G 1}}{m_{e}}, \\
2 \xi_{1} \omega_{1} & =\frac{c_{e}}{m_{e}}, \\
\beta_{0} & =\frac{1}{m_{e}}, \\
m_{e} & =m,
\end{aligned}
$$

where the symbols $\omega_{1}, \xi_{1}$, and $\beta_{0}$ are structure self-vibration frequency, damping ratio, and the reciprocal of structure mass, respectively. Moreover, $c_{e}$ and $k_{e}$ are the equivalent damping and stiffness, respectively.

According to the seismic code [39], $S_{E k}$ should be ascertained by the maximum between the following:

$$
\begin{aligned}
& S_{E k}=\sqrt{S_{x}{ }^{2}+\left(0.85 S_{y}\right)^{2}} \\
& S_{E k}=\sqrt{S_{y}{ }^{2}+\left(0.85 S_{x}\right)^{2}} .
\end{aligned}
$$

So $u_{E k}$ can be determined by the following:

$$
u_{E k}=\sqrt{\ddot{u}_{g}^{2}(t)+\left(0.85 \ddot{u}_{v}(t)\right)^{2}},
$$

where $\ddot{u}_{g}$ and $\ddot{u}_{v}$ are the horizontal and vertical acceleration, respectively.

Assume that

$$
\begin{aligned}
& \frac{\left[-m_{e}\left(\ddot{u}_{g}(t)+\ddot{u}_{v}(t)\right)+F_{0}\right]}{m_{e}}=\frac{\left[m_{e} u_{E k}+F_{0}\right]}{m_{e}} \\
& \quad=f_{1}(t) .
\end{aligned}
$$


So the time domain dynamic equation of the energy dissipation structure of a single degree of freedom with linear viscoelastic damper could be expressed in the following form:

$$
\ddot{u}+2 \xi_{1} \omega_{1} \dot{u}+\omega_{1}^{2} u+\beta_{0} \int_{0}^{t} h_{G 1}(t-\tau) \dot{u}(\tau)=f_{1}(t) .
$$

4.2. Stochastic Averaging Equation. According to the stochastic averaging theory, the standard Van-der-Pol transform is introduced:

$$
\begin{aligned}
u(t) & =A_{1}(t) \cos \theta_{1}(t), \\
\dot{u}(t) & =-A_{1}(t) \omega_{1} \sin \theta_{1}(t), \\
\theta_{1}(t) & =\omega_{1} t+\Phi_{1}(t) .
\end{aligned}
$$

The stochastic averaging equations that fit the amplitude $A_{1}(t)$ are shown in the following:

$$
\begin{aligned}
d A_{1}= & {\left[-\xi \omega_{1} A_{1}+\frac{\pi S_{f_{1}}\left(\omega_{1}\right)}{2 \omega_{1}^{2} A_{1}}\right] d t } \\
& +\frac{\left[\pi S_{f_{1}}\left(\omega_{1}\right)\right]^{1 / 2}}{\omega_{1}} d v_{1}(t) \\
d \Phi_{1}(t)= & \frac{1}{2} \beta_{0} H_{c}\left(\omega_{1}\right) d t+\frac{\left[\pi S_{f_{1}}\left(\omega_{1}\right)\right]^{1 / 2}}{A_{1} \omega_{1}} d v_{2}(t),
\end{aligned}
$$

where $d v_{1}(t)$ and $d v_{2}(t)$ are Wiener process of independent units and $S_{f_{1}}\left(\omega_{1}\right)$ is the power spectrum function of $f_{1}$ in the value of $\omega_{1}$; the expression of $\xi$ is shown in (22).

$$
\begin{gathered}
\xi=\xi_{1}+\frac{H_{c}\left(\omega_{1}\right)}{2 \omega_{1} m_{e}} \\
H_{c}\left(\omega_{1}\right)=\int_{0}^{\infty} h_{G 1}(t) \cos \omega_{1} \tau d \tau=\frac{E_{G 21}\left(\omega_{1}\right)}{\omega_{1}},
\end{gathered}
$$

where $E_{G 11}\left(\omega_{1}\right)=k_{G 1}+\omega_{1} \int_{0}^{\infty} h_{G 1}(t) \sin \omega_{1} t d t, E_{G 21}\left(\omega_{1}\right)=$ $\omega_{1} \int_{0}^{\infty} h_{G 1}(t) \cos \omega_{1} t d t$.

\subsection{The Transient Joint Probability Density Function of Each} Mode Shape of the Nonlinear Structure with Braces. Assume that the state variables of $A_{1}(t)$ and $\Phi_{1}(t)$ are $a_{1}$ and $\varphi_{1}$, respectively. Probability density function of $A_{1}(t)$ is $P_{1}\left(a_{1}, t\right)$. The transient joint probability density function of $A_{1}(t)$ and $\Phi_{1}(t)$ is $P_{1}\left(a_{1}, \varphi_{1}, t\right)$ and the transient joint probability density function of $u(t)$ and $\dot{u}(t)$ is $P_{1}(u, \dot{u}, t)$, where $u(t)$ is structure displacement and $\dot{u}(t)$ is the velocity. According to Itô equation (21), the transient joint probability density function $P_{1}\left(a_{1}, \varphi_{1}, t \mid a_{0}, \varphi_{0}, t_{0}\right)$ that fits the FPK equation is shown in the following:

$$
\begin{aligned}
\frac{\partial P_{1}}{\partial t}= & -\frac{\partial}{\partial a_{1}}\left[m_{a} P_{1}\right]-\frac{\partial}{\partial \varphi_{1}}\left[m_{\varphi} P_{1}\right] \\
& +\frac{1}{2} \frac{\partial^{2}}{\partial{a_{1}}^{2}}\left[{\sigma_{11}}^{2} P_{1}\right]+\frac{1}{2} \frac{\partial^{2}}{\partial \varphi_{1}^{2}}\left[\sigma_{22}^{2} P_{1}\right] .
\end{aligned}
$$

Because (20) does not depend on $\Phi_{1}(t)$, the probability density function $P\left(a_{1}, t \mid a_{0}, t_{0}\right)$ determined by FPK equation is as follows:

$$
\frac{\partial P_{1}}{\partial t}=-\frac{\partial}{\partial a_{1}}\left[m_{a} P_{1}\right]+\frac{1}{2} \frac{\partial^{2}}{\partial a^{2}}\left[\sigma_{11}^{2} P_{1}\right] .
$$
follows:

The initial conditions of (24) and (25) are, respectively, as

$$
\begin{aligned}
P_{1}\left(a_{1}, \varphi_{1}, t_{0} \mid a_{0}, \varphi_{0}, t_{0}\right) & =\delta_{1}\left(a_{1}-a_{0}\right) \delta_{1}\left(\varphi_{1}-\varphi_{0}\right) \\
P_{1}\left(a_{1}, t_{0} \mid a_{0}, t_{0}\right) & =\delta_{1}\left(a_{1}-a_{0}\right) .
\end{aligned}
$$

Comparing with (24) and (25), we obtain the relationship of solution under the static initial conditions the following:

$$
\begin{aligned}
P_{1}\left(a_{1}, \varphi_{1}, t\right) & =\frac{1}{2 \pi} P_{1}\left(a_{1}, t\right), \\
P\left(a_{1}, 0\right) & =\delta\left(a_{1}\right) .
\end{aligned}
$$

Meanwhile, we obtain the transient joint probability density function of the original weak nonlinear structure from transient displacement $u(t)$ and transient velocity $\dot{u}(t)$ under the static initial condition.

$$
\begin{aligned}
P_{1} & (u, \dot{u}, t) \\
& =\left.\frac{1}{\omega_{1} a_{1}} P_{1}\left(a_{1}, \varphi_{1}, t\right)\right|_{a_{1}=a_{0}} \frac{1}{2 \pi \omega_{1} a_{1}} P_{1}\left(a_{1}, t\right) \mid a_{1} \\
& =a_{0},
\end{aligned}
$$

where $a_{0}=\left(u^{2}+\dot{u}^{2} / \omega_{1}^{2}\right)^{1 / 2}$.

When the expression of $P_{1}\left(a_{1}, t\right)$ is obtained, the original structure of random response characteristics can be fully determined.

The solution of (22) and (25) should also fit $P_{1}\left(a_{1}, t\right)$ under the static initial condition. $P_{1}\left(a_{1}, t\right)$ could be written as follows:

$$
\begin{aligned}
\frac{\partial P_{1}\left(a_{1}, t\right)}{\partial t}= & \frac{\pi S_{f_{1}}\left(\omega_{1}\right)}{2 \omega_{1}{ }^{2}} \frac{\partial^{2} P_{1}}{\partial a_{1}{ }^{2}} \\
& +\frac{\partial}{\partial a_{1}}\left\{\left[\xi_{1} \omega_{1} a_{1}-\frac{\pi S_{f_{1}}\left(\omega_{1}\right)}{2 a_{1} \omega_{1}{ }^{2}}\right] P_{1}\right\},
\end{aligned}
$$

where $P\left(a_{1}, 0\right)=\delta\left(a_{1}\right)$.

Assume that the form of $P_{1}\left(a_{1}, t\right)$ is described as follows:

$$
P_{1}\left(a_{1}, t\right)=\frac{a_{1}}{c_{1}(t)} \exp \left[-\frac{a_{1}^{2}}{2 c_{1}(t)}\right],
$$

where $c_{1}(t)$ is the undetermined function.

Equation (31) is substituted into (28); we transform the system of (31) into the following form.

$$
c_{1}(t)=\frac{\pi S_{f_{1}}\left(\omega_{1}\right)}{2 \xi_{1} \omega_{1}^{3}}\left[1-e^{-2 \xi_{1} \omega_{1} t}\right] .
$$



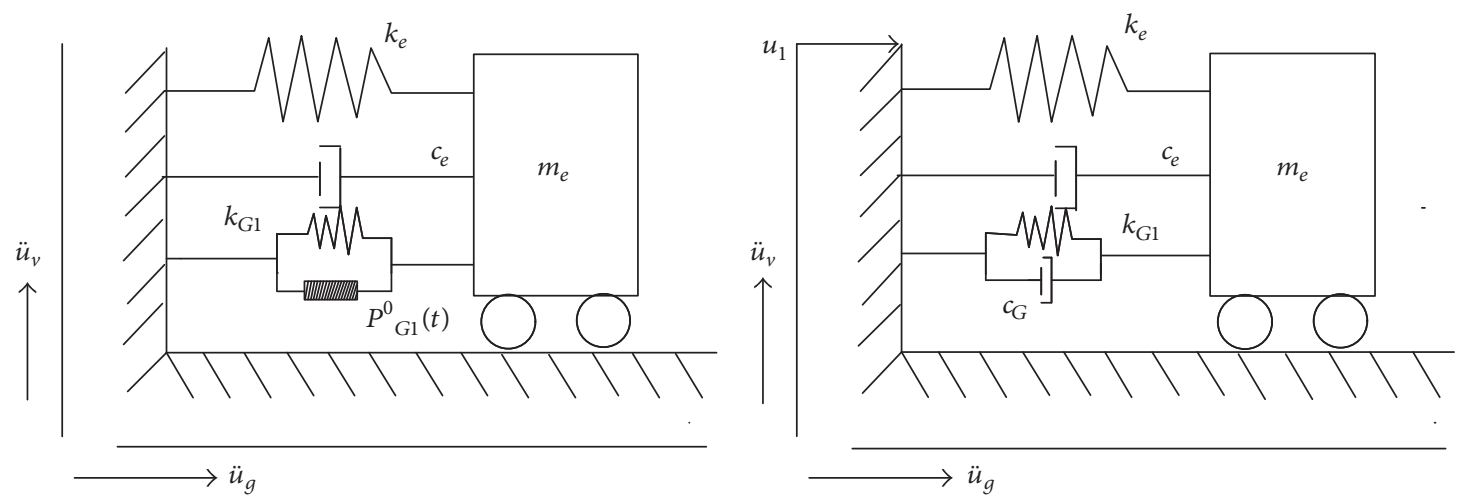

Figure 3: Calculation diagram.

Then (32) is substituted into (31); we can obtain the analytical solution of $P_{1}\left(a_{1}, t\right)$.

According to (29) and (32), we can obtain the response variance of the structural displacement and velocity, respectively.

$$
\begin{aligned}
& E\left[u^{2}(t)\right]=c_{1}(t)=\frac{\pi S_{f_{1}}\left(\omega_{1}\right)}{2 \xi_{1} \omega_{1}{ }^{3}}\left[1-e^{-2 \xi_{1} \omega_{1} t}\right], \\
& E\left[\dot{u}^{2}(t)\right]=\omega_{1}{ }^{2} c_{1}(t)=\frac{\pi S_{f_{1}}\left(\omega_{1}\right)}{2 \xi_{1} \omega_{1}}\left[1-e^{-2 \xi_{1} \omega_{1} t}\right] .
\end{aligned}
$$

\section{Equivalent Damping of Weak Nonlinear Structure with the Viscoelastic Damping and the Braces}

The actual ground motion is highly random characteristics. Because of the rationality and practicality of the earthquake, the ground motion model still needs to be further improved. So the the response spectrum method is adopted in most countries. Once the structure is installed with the damper and it turns into an energy dissipation structure, the response spectrum method can not be directly applied to these structures. Therefore, it is greatly significant to establish the equivalent structure which can be used directly with the response spectrum method. The calculation diagram is shown in Figure 3.

Where $P_{G 1}^{0}(t)=\int_{0}^{t} h_{G 1}(t-\tau) \dot{u}(\tau) d \tau$ is the equivalent to a damping force of $c_{G} \dot{u}$ from (4), the motion equation of the structure can be described as follows:

$$
\begin{gathered}
m_{e} \ddot{u}+\left(c_{e}+c_{G}\right) \dot{u}+\left(k_{e}+k_{G 1}\right) u \\
=-m_{e}\left(\ddot{u}_{g}(t)+\ddot{u}_{v}(t)\right)+F_{0}
\end{gathered}
$$

In this case, (35) may be written as the following form:

$$
\ddot{u}+2\left(\xi_{1}+\xi_{G}\right) \omega_{1} \dot{u}+\omega_{1}^{2} u=f_{1}(t),
$$

where $\xi_{G}=c_{G} / 2 m_{e} \omega_{1}, f_{1}(t)=\left(-m_{e}\left(\ddot{u}_{g}(t)+\ddot{u}_{v}(t)\right)+F_{0}\right) / m_{e}$.

According to the stochastic averaging method, it is known that the probability density function of the amplitude response $\left(A_{1}(t)\right)$ of the equivalent structure is $P_{1}\left(a_{1}, t\right)$. The probability density function fitting the FPK equation is as follows:

$$
\begin{aligned}
& \frac{\partial P_{1}\left(a_{1}, t\right)}{\partial t} \\
& =\frac{\pi S_{f_{1}}\left(\omega_{1}\right)}{2 \omega_{1}^{2}} \frac{\partial^{2} P_{1}}{\partial a_{1}^{2}} \\
& \quad+\frac{\partial}{\partial a_{1}}\left\{\left[\left(\xi_{1}+\xi_{G}\right) \omega_{1} a_{1}-\frac{\pi S_{f_{1}}\left(\omega_{1}\right)}{2 a_{1} \omega_{1}^{2}}\right] P_{1}\right\}
\end{aligned}
$$

The amplitude probability density function of the original structure can be applied to (30); the amplitude probability density function of the equivalent structure is appropriate for (37). We will know the difference by comparing with (30) and (37). After the following processing, the expression can be expressed as follows:

$$
\begin{aligned}
\xi_{G} & =\frac{H_{c}\left(\omega_{1}\right)}{2 \omega_{1} m_{e}}=\frac{E_{G 21}\left(\omega_{1}\right)}{\omega_{1}} \cdot \frac{1}{2 \omega_{1} m_{e}}=\frac{E_{G 21}\left(\omega_{1}\right)}{2 \omega_{1}^{2} m_{e}} \\
c_{G} & =\frac{E_{G 21}\left(\omega_{1}\right)}{\omega_{1}}, \\
k_{G 1} & =\frac{k_{b 1} k_{Q 1}}{k_{b 1}+k_{Q 1}},
\end{aligned}
$$

where $\xi_{G}$ is the equivalent damping ratio of damper; it is consistent with the equivalent damping ratio of the Maxwell damper with the general integral model. For arbitrary random biaxial earthquake excitations $\ddot{u}_{g}(t)$ and $\ddot{u}_{v}(t)$, all stochastic response characteristics calculated with the proposed method in equivalent structure are the same as these of the original structure. The equivalent damping ratio of the whole weak nonlinear dissipation structure is established as follows:

$$
\xi_{z}=\xi_{1}+\xi_{G}
$$



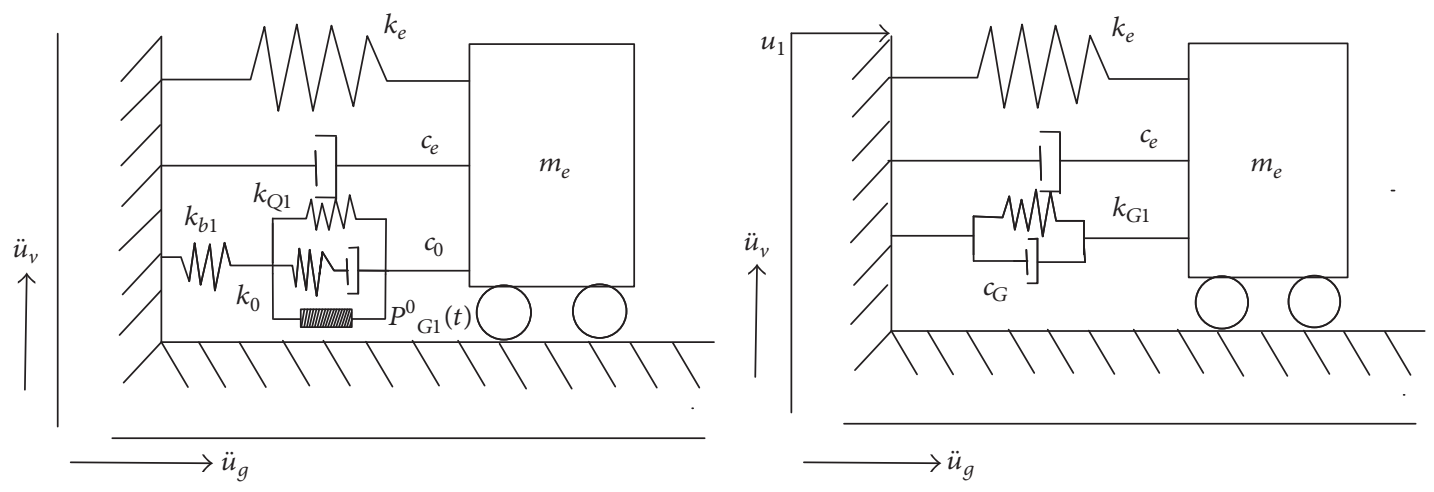

FIgURE 4: Calculation diagram.

That is, the equivalent structure can be used as a total equivalent ratio of $\xi_{z}$ instead of the original structure damping ratio $\xi_{1}$; then we can use response spectrum method for structural analysis and engineering design.

\section{Numerical Example}

It shows a SDOF nonlinear generalized Maxwell damper energy dissipation structure and the equivalent structure in Figure 4; the earthquake intensity is 8 degrees $(0.2 \mathrm{~g})$; its mass, stiffness, damping, and damping ratio are, respectively, $m_{e}=2 \mathrm{~kg}, k_{e}=100 \mathrm{~N} / \mathrm{m}, c_{e}=2 \mathrm{~N} \cdot \mathrm{s} / \mathrm{m}$, and $\xi_{1}=0.05$. The nonlinear structure is subjected to transient forces under biaxial earthquake. $S_{f_{1}}=f_{1}(0)=500 \times 10^{-6}\left(\mathrm{~m}^{2} / \mathrm{s}^{3}\right)$, $T=0.2 \mathrm{~s}$. The performance parameters of Maxwell damper in parallel are listed as follows: the brace $k_{b 1}=200 \mathrm{~N} / \mathrm{m}$, equilibrium modulus $k_{\mathrm{Q} 1}=200 \mathrm{~N} / \mathrm{m}, h_{\mathrm{Q} 1}=200 \mathrm{~s}^{-2}$, element damping coefficient $c_{0}=30 \mathrm{~N} \cdot \mathrm{s} / \mathrm{m}$, and the stiffness $k_{0}=50 \mathrm{kN} / \mathrm{m}$. The excellent frequency and damping ratio of the site are $\omega_{g 1}=9.67 \mathrm{~s}^{-1}$ and $\xi_{g_{1}}=0.9$, respectively. Spectral intensity factor $S_{0}=0.01387 \mathrm{~m}^{2} / \mathrm{s}^{3}$. According to the equivalent damping ratio formula, when $t=0.2 \mathrm{~s}$, the attached equivalent damping ratio $\xi_{G}$ of damper and the response variance of equivalent structural displacement are calculated; the response variance of original structure is also obtained by the frequency domain method.

$$
\begin{aligned}
E_{\mathrm{Q} 11} & =K_{00}+\frac{K_{0} \rho_{0}{ }^{2} \omega_{1}^{2}}{1+\rho_{0}^{2} \omega_{1}^{2}}, \\
E_{\mathrm{Q} 21}\left(\omega_{1}\right) & =\frac{c_{0} \omega_{1}}{1+\rho_{0}{ }^{2} \omega_{1}^{2}}=\frac{30 \times 10}{1+0.36 \times 100}=\frac{300}{37} \\
& =8.1 \mathrm{~N} / \mathrm{m}, \\
K_{\mathrm{Q} 1} & =E_{\mathrm{Q} 11}(0)=K_{00} \\
\rho_{0} & =\frac{c_{0}}{k_{0}}=\frac{30}{k_{0}}=0.6
\end{aligned}
$$

$$
\begin{aligned}
E_{\mathrm{Q} 11}\left(\omega_{1}\right) & =k_{\mathrm{Q} 1}+\omega_{1} \int_{0}^{\infty} h_{\mathrm{Q} 1}(t) \sin \omega_{1} t d t \\
K_{\mathrm{Q} 1} & =E_{\mathrm{Q} 11}(0)=K_{00}=k_{\mathrm{Q} 1}+10 \times 0 \\
& =200 \mathrm{~N} / \mathrm{m} \\
K_{1} & =E_{\mathrm{Q} 11}(1)=k_{\mathrm{Q} 1}+1 \cdot 200 \cdot(-\cos 0.2) \\
& =200-200 \times 0.98=4 \mathrm{~N} / \mathrm{m} \\
E_{\mathrm{Q} 11} & =200+\frac{K_{1} \times 0.36 \times 100}{1+0.36 \times 100}=200+\frac{144}{37} \\
& =203.89 \mathrm{~N} / \mathrm{m} .
\end{aligned}
$$

According to (2), (14), and (35), we can obtain the value of the following parameters:

$$
\begin{aligned}
k_{\mathrm{G} 1} & =\frac{k_{b 1} k_{\mathrm{Q} 1}}{k_{b 1}+k_{\mathrm{Q} 1}}=\frac{200 \times 200}{200+200}=100 \mathrm{~N} / \mathrm{m} \\
\omega_{1}{ }^{2} & =\frac{k_{e}}{m_{e}}+\frac{k_{b 1} k_{\mathrm{Q} 1}}{m_{e}\left(k_{b 1}+k_{\mathrm{Q} 1}\right)} \\
& =\frac{100}{2}+\frac{200 \times 200}{2 \times(200+200)}=100 \mathrm{~s}^{-2} \\
\omega_{1} & =10 \mathrm{~s}^{-1} \\
c_{G} & =\frac{E_{\mathrm{G} 21}\left(\omega_{1}\right)}{\omega_{1}} \cdot \frac{1}{\omega_{1}} .
\end{aligned}
$$


Hence,

$$
\begin{aligned}
& c_{G}=\frac{k_{b 1}{ }^{2} \cdot \omega_{1} \int_{0}^{\infty} h_{\mathrm{Q} 1}(t) \cos \omega_{1} t d t}{\left(k_{b 1}+k_{\mathrm{Q} 1}+\omega_{1} \int_{0}^{\infty} h_{\mathrm{Q} 1}(t) \sin \omega_{1} t d t\right)^{2}+\left(\omega_{1} \int_{0}^{\infty} h_{\mathrm{Q} 1}(t) \cos \omega_{1} t d t\right)^{2}} \\
& \mathcal{c}_{G}=\frac{k_{b 1}{ }^{2}\left(c_{0} /\left(1+\rho_{0}{ }^{2} \omega_{1}{ }^{2}\right)\right)}{\left[k_{b 1}+E_{\mathrm{Q} 11}\left(\omega_{1}\right)\right]^{2}+E^{2}{ }_{\mathrm{Q} 21}\left(\omega_{1}\right)}=\frac{200^{2} \times(30 /(1+0.36 \times 100))}{(200+203.89)^{2}+8.1^{2}}=\frac{32432.4324}{163127.132+65.61}=\frac{32432.4324}{163192.74}=0.199 .
\end{aligned}
$$

The total coefficient of the parallel spring group is equal to the sum of the coefficients of each spring:

$$
k_{z}=k_{G 1}+k_{0}+k_{e}=100+50+100=250 \mathrm{~N} / \mathrm{m}
$$

According to (36), $\xi_{z}$ can be calculated as follows:

$$
\begin{aligned}
\xi_{z} & =\xi_{1}+\xi_{G}=\frac{c_{e}}{2 m_{e} \omega_{1}}+\frac{c_{G}}{2 m_{e} \omega_{1}}=0.05+0.005 \\
& =0.055
\end{aligned}
$$

From (32) and (34), we can conduct the following calculations:

$$
\begin{aligned}
c_{1}(t) & =\frac{\pi S_{f 1}\left(\omega_{1}\right)}{2 \xi_{z} \omega_{1}^{3}}\left[1-e^{-2 \xi_{z} \omega_{1} t}\right] \\
& =\frac{\pi S_{f_{1}}\left(\omega_{1}\right)}{2 \xi_{z} \omega_{1}^{3}}\left[1-e^{-2 \xi_{z} \omega_{1} \times 0.2}\right] \\
& =\frac{3.14 \times 500}{2 \times 0.055 \times 10^{3}}\left(1-e^{-2 \times 0.055 \times 10 \times 0.2}\right) \times 10^{-6} \\
& =\frac{1570}{110} \times\left(1-e^{-0.22}\right) \times 10^{-6} \\
& =14.27 \times 0.2 \times 10^{-6}=2.854 \times 10^{-6} \mathrm{~m}^{2} .
\end{aligned}
$$

Hence, we can obtain the following parameters values:

$$
\begin{aligned}
\sigma_{u}{ }^{2} & =E\left[u^{2}(t)\right]=c_{1}(t)=\frac{\pi S_{f 1}\left(\omega_{1}\right)}{2 \xi_{z} \omega_{1}^{3}}\left[1-e^{-2 \xi_{z} \omega_{1} t}\right] \\
& =2.854 \times 10^{-6} \mathrm{~m}^{2} \\
{\sigma_{\dot{u}}}^{2} & =E\left[\dot{u}^{2}(t)\right]=\omega_{1}^{2} c_{1}(t) \\
& =\frac{\pi S_{f_{1}}\left(\omega_{1}\right)}{2 \xi_{z} \omega_{1}}\left[1-e^{-2 \xi_{z} \omega_{1} t}\right] \\
& =\frac{3.14 \times 500}{2 \times 0.055 \times 10}\left(1-e^{-2 \times 0.055 \times 10 \times 0.2}\right) \times 10^{-6}
\end{aligned}
$$

$$
\begin{aligned}
& =\frac{1570}{1.1} \times\left(1-e^{-0.22}\right) \times 10^{-6} \\
& =1427.27 \times(1-0.8) \times 10^{-6} \\
& =0.285 \times 10^{-3} \mathrm{~m}^{2} \cdot \mathrm{s}^{-2} \cdot \sigma_{u \max }^{2}=\frac{\pi S_{f_{1}}\left(\omega_{1}\right)}{2 \xi_{z} \omega_{1}^{3}} \\
& =\frac{3.14 \times 500}{2 \times 0.055 \times 10^{3}}=14.27 \times 10^{-6} \mathrm{~m}^{2} \times 10^{-6} .
\end{aligned}
$$

According to the frequency domain method, frequency response function and the variance of displacement are obtained, respectively.

$$
\begin{aligned}
H_{u}\left(\omega_{1}\right)= & \frac{B_{0}+B_{1}\left(i \omega_{1}\right)}{A_{0}+A_{1}\left(i \omega_{1}\right)+A_{2}\left(i \omega_{1}\right)^{2}+A_{3}\left(i \omega_{1}\right)^{3}}, \\
\sigma_{u}^{2}= & \int_{-\infty}^{\infty}\left|H_{u}\left(\omega_{1}\right)\right|^{2} S_{f_{1}} d \omega_{1} \\
= & \frac{\pi S_{f_{1}}\left(A_{0} B_{1}^{2}+A_{2} B_{0}^{2}\right)}{A_{0}\left(A_{1} A_{2}-A_{0} A_{3}\right)} \\
= & \frac{3.14 \times 500 \times\left(100 \times 0.6^{2}+1.6 \times 1^{2}\right)}{100 \times(76 \times 1-100 \times 0.6)} \\
& \times 10^{-6}=9.58 \times 10^{-6} \mathrm{~m}^{2},
\end{aligned}
$$

where

$$
B_{0}=1
$$$$
B_{1}=\frac{c_{0}}{k_{0}}=\frac{30}{50}=0.6 \text {, }
$$$$
A_{0}=\frac{k_{e}+k_{\mathrm{G} 1}}{m_{e}}=\frac{200}{2}=100,
$$$$
A_{3}=\frac{c_{0}}{k_{0}}=0.6
$$

$$
\begin{aligned}
A_{1} & =\frac{c_{e}}{m_{e}}+\frac{\left(k_{e}+k_{\mathrm{G} 1}\right) c_{0}}{k_{0} m_{e}}+\frac{c_{0}}{m_{e}}=\frac{2}{2}+\frac{200 \cdot 30}{50 \cdot 2}+\frac{30}{2} \\
& =76
\end{aligned}
$$$$
A_{2}=1+\frac{c_{e} c_{0}}{m_{e} k_{0}}=1+\frac{2 \cdot 30}{2 \cdot 50}=1.6
$$ 
TABLE 1: Results comparison of the frequency domain method and the proposed method in this paper.

\begin{tabular}{lccc}
\hline $\begin{array}{l}\text { Damping coefficient } \\
c_{0} / \mathrm{N} \cdot \mathrm{s} / \mathrm{m}\end{array}$ & $\begin{array}{c}\text { Approximate calculation formula of } \\
\text { frequency domain method }\end{array}$ & \multicolumn{2}{c}{ Method proposed in this paper } \\
\hline 10 & 2.7 & 3.897 & 3.3 \\
15 & 2.950 & 3.867 & 3.1 \\
20 & 2.950 & 3.838 & 30.1 \\
25 & 3.032 & 3.809 & 25.6 \\
30 & 3.095 & 3.778 & 22.1 \\
35 & 3.145 & 3.751 & 19.3 \\
40 & 3.186 & 3.724 & 16.9 \\
45 & 3.223 & 3.695 & 14.6 \\
\hline
\end{tabular}

The relative error can be calculated.

$$
\text { Error } \%=\frac{|\sqrt{14.270}-\sqrt{9.58}|}{\sqrt{9.58}}=0.221 .
$$

It is known that we have calculated the maximum displacement standard deviation by frequency domain method and equivalent structure. The results of maximum displacement standard deviation are given in Table 1. Results of the two methods are gradually approaching with the increase of the damping coefficient. The maximum displacement relative error is gradually reduced with the increase of the damping coefficient. When $C_{0}$ increases to a certain value, the results have a higher precision accuracy.

\section{Conclusions}

In this paper, a weak nonlinear structural system with one degree of freedom is researched and a systematically research on the random response characteristic of structure was conducted, which is under biaxial earthquake action. First, integral constitutive relation is adopted; it then establishes a differential and integral equations of motion of SDOF weak nonlinear structure containing the general integral model viscoelastic dampers and the braces. And, then, the motion equation is linearized according to the principle of energy balance. Finally, based on the stochastic averaging method, the general analytical solution of the variance of the displacement, velocity response, and equivalent damping is deduced and derived. The joint probability density function of the amplitude and phase and displacement and velocity of the energy dissipation structure are also given at the same time. Numerical example shows the availability and accuracy of the proposed method. It means it has established a complete analytical solution of stochastic response analysis and equivalent damping of a SDOF nonlinear dissipation structure with the brace under biaxial earthquake action in this paper. The proposed method provides a beneficial reference for the engineering design of this kind of structure.

\section{Conflicts of Interest}

The authors declare that they have no conflicts of interest.

\section{Acknowledgments}

This study is supported by the National Natural Science Foundation of China (51569005, 51468005, and 51469005), Guangxi Natural Science Foundation of China (2015GXNSFAA139279 and 2014GXNSFAA118315), Innovation Project of Guangxi Graduate Education in China (GKYC201628, GKYC201711, and YCSZ2015207), and Innovation Team of Guangxi University of Science and Technology 2015.

\section{References}

[1] M. Asano, Y. Yamano, K. Yoshie, Y. Koike, K. Nakagawa, and T. Murata, "Development of active-damping bridges and its application to triple high-rise buildings," JSME International Journal, Series C: Mechanical Systems, Machine Elements and Manufacturing, vol. 46, no. 3, pp. 854-860, 2003.

[2] A. V. Bhaskararao and R. S. Jangid, "Seismic analysis of structures connected with friction dampers," Engineering Structures, vol. 28, no. 5, pp. 690-703, 2006.

[3] Y. L. Xu, Q. He, and J. M. Ko, "Dynamic response of damperconnected adjacent buildings under earthquake excitation," Engineering Structures, vol. 21, no. 2, pp. 135-148, 1999.

[4] Y. L. Xu, S. Zhan, J. M. Ko et al., "Experimental investigation of adjacent buildings connected by fluid damper," Earthquake Engineering \& Structural Dynamics, vol. 28, no. 6, pp. 609-631, 1999.

[5] W. S. Zhang and Y. L. Xu, "Vibration analysis of two buildings linked by maxwell model-defined fluid dampers," Journal of Sound \& Vibration, vol. 233, no. 5, pp. 775-796, 2000.

[6] S. D. Bharti, S. M. Dumne, and M. K. Shrimali, "Seismic response analysis of adjacent buildings connected with MR dampers," Engineering Structures, vol. 32, no. 8, pp. 2122-2133, 2010.

[7] R. E. Christenson, B. F. Spencer, and E. A. Johnson, "Semiactive connected control method for adjacent multidegree-offreedom buildings," Journal of Engineering Mechanics, vol. 133, no. 3, pp. 290-298, 2007.

[8] Y. L. Xu and C. L. Ng, "Seismic protection of a building complex using variable friction damper: experimental investigation," Journal of Engineering Mechanics, vol. 134, no. 8, pp. 637-649, 2008. 
[9] R. E. Christenson, B. F. Spencer Jr., N. Hori, and K. Seto, "Coupled building control using acceleration feedback," ComputerAided Civil and Infrastructure Engineering, vol. 18, no. 1, pp. 418, 2003.

[10] Y. Zhang and W. D. Iwan, "Statistical performance analysis of seismic-excited structures with active interaction control," Earthquake Engineering \& Structural Dynamics, vol. 32, no. 7, pp. 1039-1054, 2003.

[11] T. T. Soong and G. F. Dargush, Passive Energy Dissipation Systems in Structural Engineering, John, Wiley and Ltd, England, 1997.

[12] S. W. Park, "Analytical modeling of viscoelastic dampers for structural and vibration control," International Journal of Solids and Structures, vol. 38, no. 44-45, pp. 8065-8092, 2001.

[13] K.-C. Chang and Y.-Y. Lin, "Seismic response of full-scale structure with added viscoelastic dampers," Journal of Structural Engineering, vol. 130, no. 4, pp. 600-608, 2004.

[14] J. S. Hwang and J. C. Wang, "Seismic response prediction of HDR bearings using fractional derivative Maxwell model," Engineering Structures, vol. 20, no. 9, pp. 849-856, 1998.

[15] A. Aprile, J. A. Inaudi, and J. M. Kelly, "Evolutionary model of viscoelastic dampers for structural applications," Journal of Engineering Mechanics, vol. 123, no. 6, pp. 551-560, 1997.

[16] R. Lewandowski and B. Chorążyczewski, "Identification of the parameters of the Kelvin-Voigt and the Maxwell fractional models, used to modeling of viscoelastic dampers," Computers and Structures, vol. 88, no. 1-2, pp. 1-17, 2010.

[17] M. Amjadian and A. K. Agrawal, "Analytical modeling of a simple passive electromagnetic eddy current friction damper," in Active and Passive Smart Structures and Integrated Systems 2016, Proceedings of SPIE 9799, March 2016.

[18] J. A. Fabunmi, "Extended damping models for vibration data analysis," Journal of Sound \& Vibration, vol. 101, no. 2, pp. 181192, 1985.

[19] G. Pekcan, B. J. Mander, and S. S. Chen, "Fundamental considerations for the design of non-linear viscous dampers," Earthquake Engineering \& Structural Dynamics, vol. 28, no. 11, pp. 1405-1425, 1999.

[20] S. Rakheja and S. Sankar, "Local equivalent constant representation of nonlinear damping mechanisms," Engineering Computations, vol. 3, no. 1, pp. 11-17, 1986.

[21] J. B. Roberts, "Literature review : response of nonlinear mechanical systems to random excitation part 2: equivalent linearization and other methods," Shock \& Vibration Digest, vol. 13, no. 5, pp. 13-29, 1981.

[22] D. W. Malone and J. J. Connor, "Transient dynamic response of linearly viscoelastic structures and continua," in Proceedings of the Structural Dynamics Aeroelasticity Specialisted Conference, pp. 349-356, AIAA, New Orleans, La, USA, 1969.

[23] Y. Kitagawa, Y. Nagataki, and T. Kashima, "Dynamic response analyses with effects of strain rate and stress relaxation," Transactions of the Architectural Institute of Japan, pp. 32-41, 1984.

[24] H. J. Park, J. Kim, and K. W. Min, "Optimal design of added viscoelastic dampers and supporting braces," Earthquake Engineering \& Structural Dynamics, vol. 33, no. 4, pp. 465-484, 2004.

[25] M. P. Singh, N. P. Verma, and L. M. Moreschi, "Seismic analysis and design with Maxwell dampers," Journal of Engineering Mechanics, vol. 129, no. 3, pp. 273-282, 2003.

[26] Y. Chen and Y. H. Chai, "Effects of brace stiffness on performance of structures with supplemental Maxwell model-based brace-damper systems," Earthquake Engineering \& Structural Dynamics, vol. 40, no. 1, pp. 75-92, 2010.
[27] S. L. Xun, "Study on the calculation formula of equivalent damping ratio of viscous dampers," Engineering Earthquake Resistance and Reinforcement and Reconstruction, vol. 36, no. 5, pp. 52-56, 2014.

[28] H. Wenfu, C. Chengyuan, and L. Yang, "A comparative study on the calculation method of equivalent damping ratio of viscous dampers," Shanghai: Structural Engineer, vol. 32, no. 1, pp. 10-16, 2016.

[29] Y.-H. Li and B. Wu, "Determination of equivalent damping relationships for direct displacement-based seismic design method," Advances in Structural Engineering, vol. 9, no. 2, pp. 279-291, 2006.

[30] Y. Yang, W. Xu, Y. Sun et al., "Stochastic response of nonlinear vibroimpact system with fractional derivative excited by Gaussian white noise," Communications in Nonlinear Science \& Numerical Simulation, 2016.

[31] Y. Wu and W. Fang, "Stochastic averaging method for estimating first-passage statistics of stochastically excited DuffingRayleigh-Mathieu system," Acta Mechanica Sinica/Lixue Xuebao, vol. 24, no. 5, pp. 575-582, 2008.

[32] H. Xiong and W. Q. Zhu, "A stochastic optimal control strategy for viscoelastic systems with actuator saturation," Probabilistedic Engineering Mechanics, vol. 45, pp. 44-51, 2016.

[33] L. Chuang di, G. X. Guang, and L. Yunjun, "Random response of structures with viscous damping and viscoelastic damper," Journal of Applied Mechanics, vol. 28, no. 3, pp. 219-225, 2011.

[34] L. Chuang di, G. X. Guang, and L. Yun jun, "Effective damping of damping structure of viscous and viscoelastic dampers," Journal of Applied Mechanics, vol. 28, no. 4, pp. 328-333, 2011.

[35] B.-C. Wen, Y.-N. Li, and Q.-K. Han, Analytical Methods And Engineering Application of The Theory of Nonlinear Vibration, Northeastern University Press, Shenyang, China, 2001.

[36] Fang-Tong, Vibration of Engineering, National Defence Industry Press, Beijing, China, 1995.

[37] Y. K. Lin, "Some observations on the stochastic averaging method," Probabilistic Engineering Mechanics, vol. 1, no. 1, pp. 23-27, 1986.

[38] W.-Q. Zhu, Random Vibration, Science Press, Beijing, China, 1998.

[39] GB/T 50011-2010, Code for Seismic Design of Buildings, China building industry press, Beijing, China, 2016. 


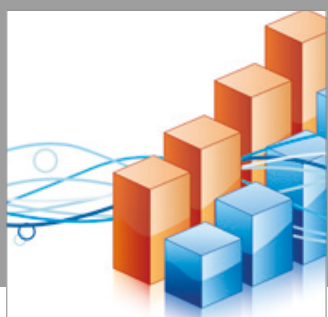

Advances in

Operations Research

vatersals

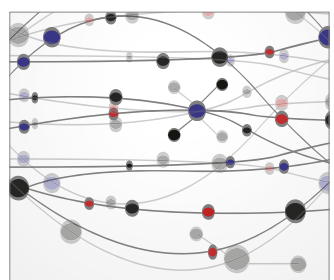

\section{The Scientific} World Journal
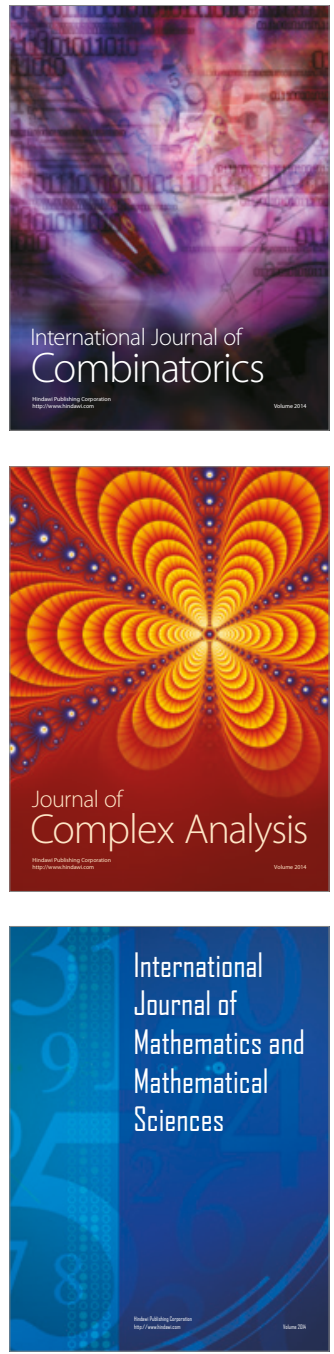
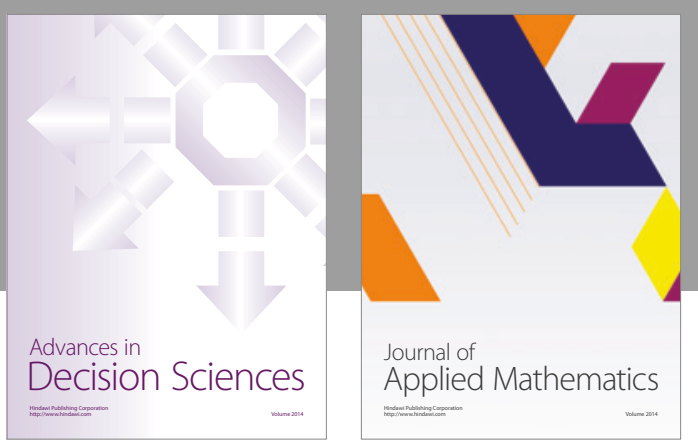

Algebra

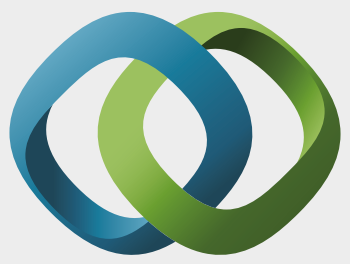

\section{Hindawi}

Submit your manuscripts at

https://www.hindawi.com
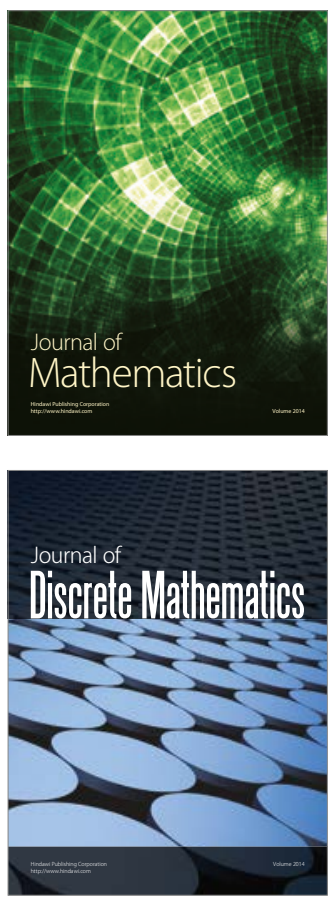

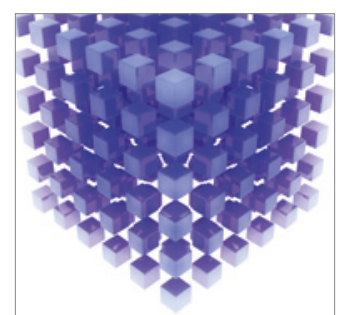

Mathematical Problems in Engineering
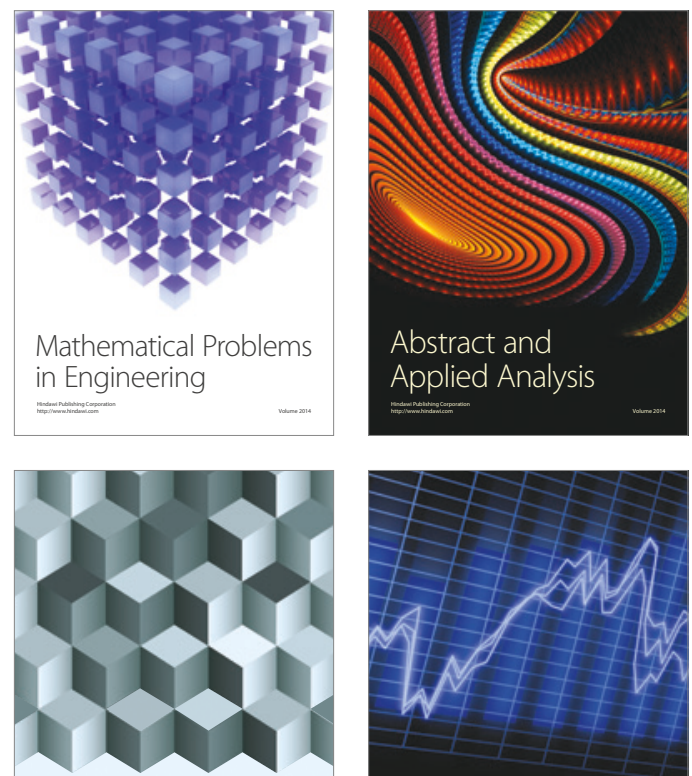

Journal of

Function Spaces

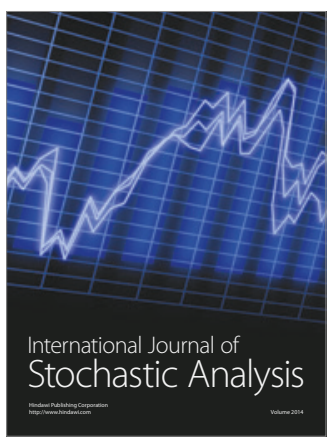

Probability and Statistics
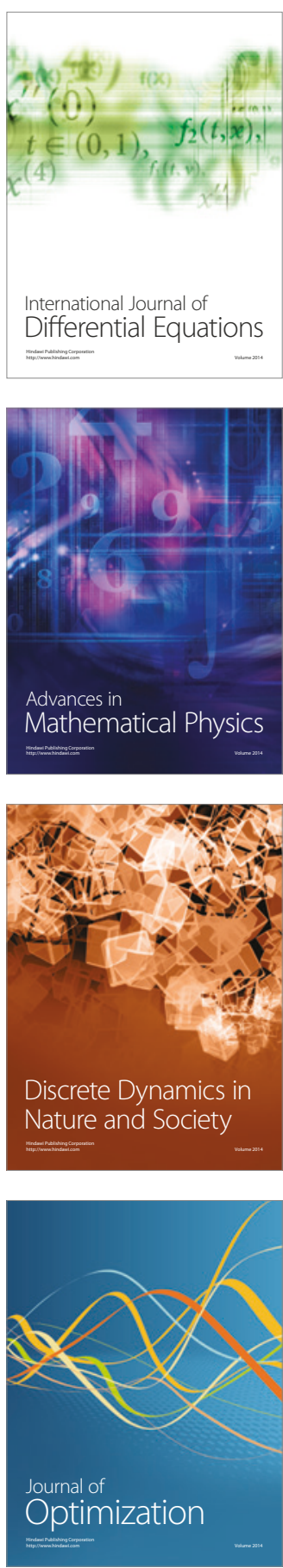